\title{
Speech Controlled Home Automation Using Raspberry Pi with Google Voice Assistance
}

\author{
P. Raghupathy, S. Nagaraj
}

\begin{abstract}
The aim of the project is to monitor and control the home appliance using IoT with help of the Google voice assistance. The system consists of the Raspberry PI to perform the total operation and Relay for trig the Loads or home appliances. These Home appliances are interlinked with the IoT (internet of things). We can access the loads, control and monitor anywhere in the world. If we adapt this system for any city and urban areas to save energy and sustainable life style. It will provide good communication compare to automated homes and normal homes.
\end{abstract}

Keywords--- IoT, Raspberry Pi, Google Voice Assistance.

\section{INTRODUCTION}

Sometimes most of the peoples forget tune off/on the loads or home appliance in home like lights, fans...etc.if they went out from home or office the power energy is waste due continuously power or loads are on condition. This may waste person time and cost .so improves this system we are moving to the proposed system. The proposed system have controlled with IoT application. This technology combines communication and information. These systems communicate with Local area network and WLAN. By using this technology is used to monitor and control the system.

\section{Existing System}

In existing system we controlled home appliance with help of different communication techniques. Like zigbee, Bluetooth...

\section{Proposed System}

To overcome the Existing system we are moving to the proposed system. In this proposed system we control and monitor the home appliance using Google voice assistance.

\section{BLOCK DIAGRAM}

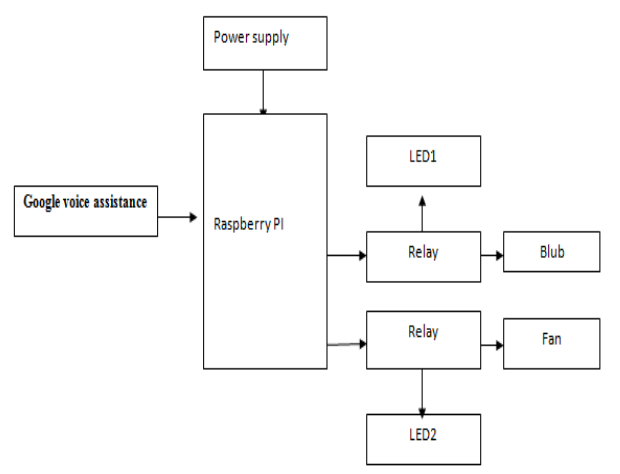

Figure 1: block diagram of the proposed system

\footnotetext{
Manuscript received September 16, 2019.

P. Raghupathy, (M.Tech), Dept. of ECE, SVCET, Chittoor, AP,
} India.

S. Nagaraj, M.Tech, (Ph.D), Asso. Prof., Dept. of ECE, SVCET, Chittoor, AP, India.

\section{Hardware Components \\ a.1) Raspberry Pi $3 \mathrm{B+}$}

The raspberry PI is a small ATM card size PC. It is a 64 bit quad core processor running at $1.4 \mathrm{GHz}$, dual-band 2.4 $\mathrm{GHz}$ and $5 \mathrm{GHz}$ wireless LAN, Bluetooth 4.2/BLE, faster Ethernet.

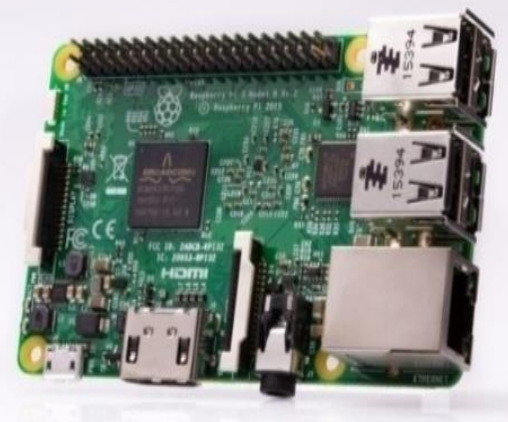

Figure 2: Raspberry Pi3 module

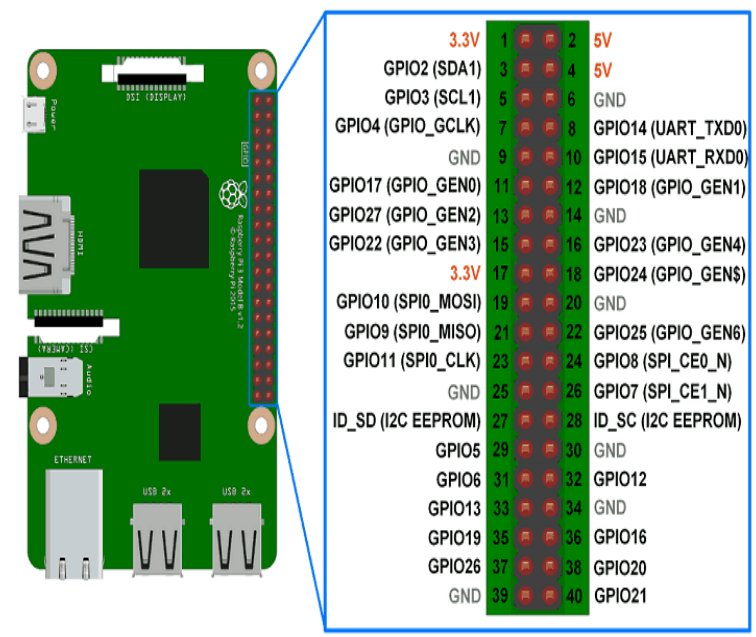

Figure 3: Pin layout of raspberry Pi GPIO used in system

a.2) Raspberry Pi model 3 B+ Specs

1. SOC: Broadcom BCM2837B0, Cortex-A53 (ARMv8) 64-bit SoC

2. CPU: $1.4 \mathrm{GHz}$ 64-bit quad-core ARM Cortex-A53 CPU

3. RAM: 1GB LPDDR2 SDRAM

4. WIFI: Dual-band $802.11 \mathrm{ac}$ wireless LAN $(2.4 \mathrm{GHz}$ and $5 \mathrm{GHz}$ ) and Bluetooth 4.2

Published By:

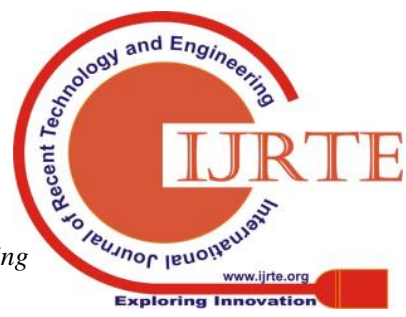




\section{SPEECH CONTROLLED HOME AUTOMATION USING RASPBERRY PI WITH GOOGLE VOICE ASSISTANCE}

5. Ethernet: Gigabit Ethernet over USB $2.0(\max 300$ Mbps). Power-over-Ethernet support (with separate PoE HAT). Improved PXE network and USB massstorage booting.

6. Thermal management: Yes

7. Video: Yes - Video Core IV 3D. Full-size HDMI

8. Audio: Yes

9. USB 2.0: 4 ports

10. GPIO: 40 -pin

11. Power: 5 V/2.5A DC power input

12. Operating system support: Linux and Unix

a.3) Raspberry Pi Thermal Performance: Cooler is better

The $\mathrm{Pi} 3 \mathrm{~B}+$ benefited from a change to the way the system-on-chip (SoC) is attached to the circuit board, allowing it to better dissipate heat. With the $3 \mathrm{~A}+$ having a smaller board, this test captures thermal images under heavy CPU load to show how well the two designs cope.

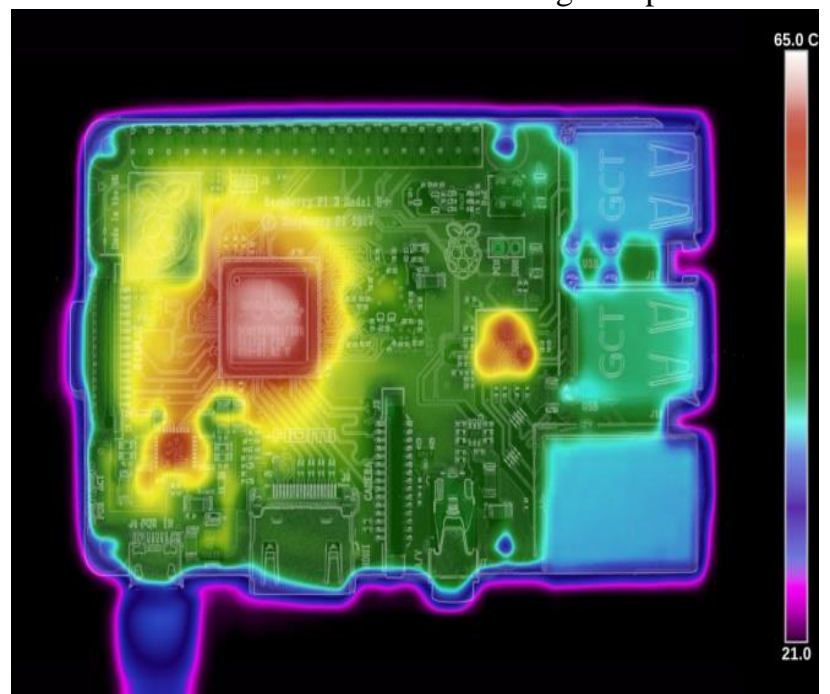

Figure 4: Raspberry Pi 3B+ thermal image (above)

b) Power Supply

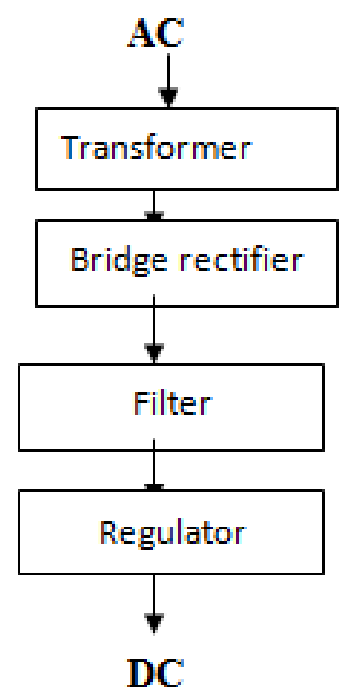

Fig. 5: Flow chart of power supply

c) Relay

Relay is electromagnetic switch and which is operate load for turn on and turn off. These are used in switching circuit applications.
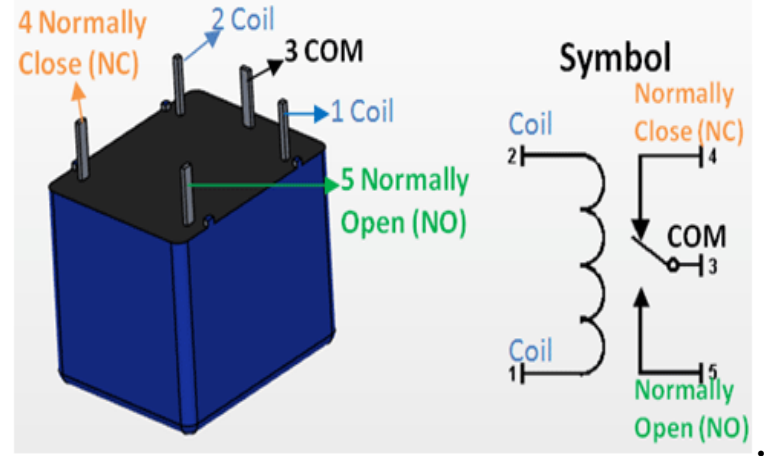

Figure 6: Relay

d) Motor

DC motors are used to convert the electrical energy into mechanical energy. These are used in the robotics, fan, and compressors applications

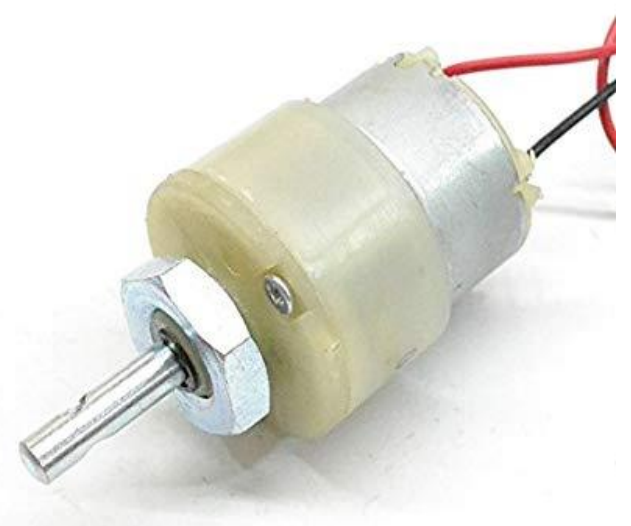

Fig. 7: DC motor

Brushed DC Motor

Anatomy

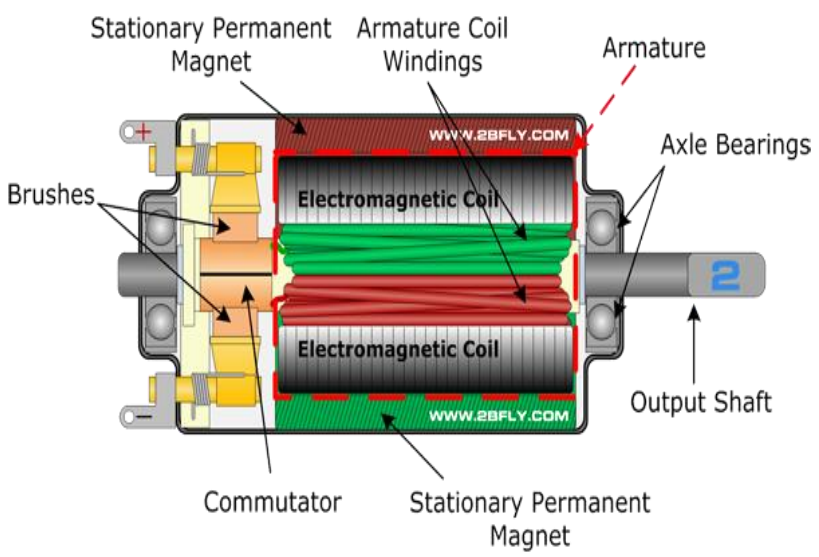

Fig. 8: Inside DC motor

\section{SOFTWARE COMPONENTS}

a) Raspbian $O S$

Raspbain is debain based operating system for raspberry PI. Raspbain improved in windows environment.

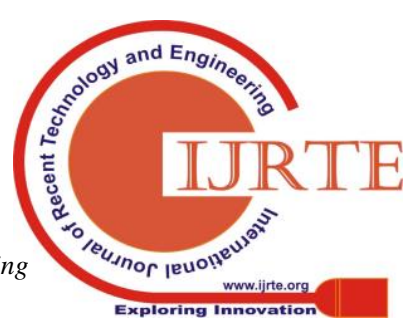




\section{Working Principle}

The project operation is simple. We can control the loads by using Raspberry PI and giving commands from Google assistance to Raspberry PI. According to the given commands the raspberry pi will turn on /turn off the loads through the Wi-Fi connectivity.

\section{Applications}

- This system is used in homes, offices, industrial areas.

\section{Advantages}

- Smart and secure.

- Controlling home appliances from anywhere in the world.

\section{RESULTS}

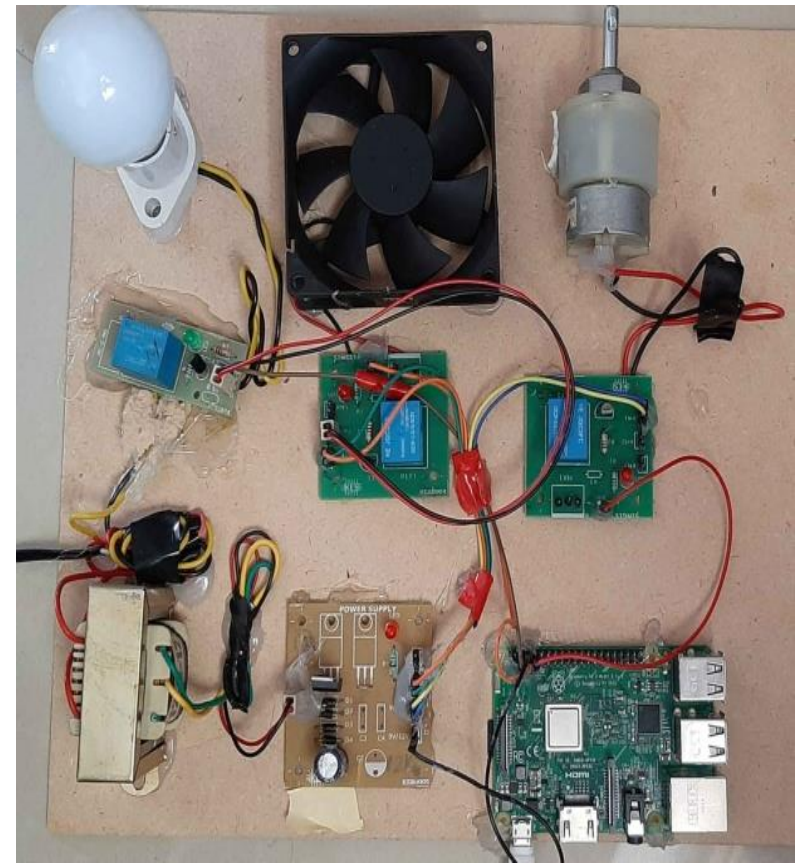

Fig. 9: Hardware design of the project

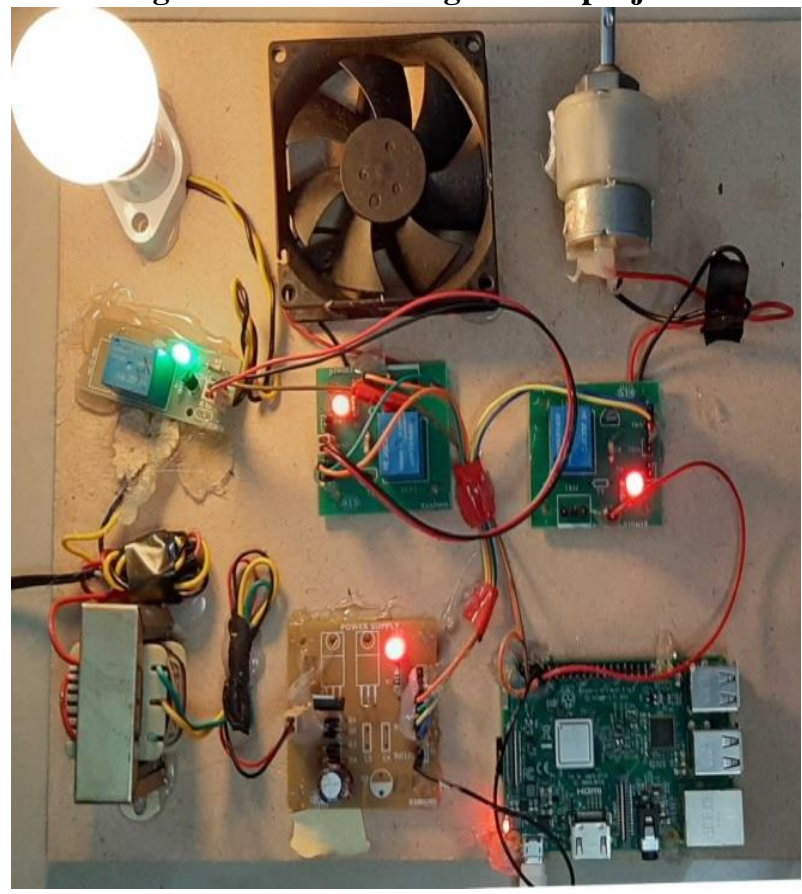

Fig. 10: Google voice assistance for light on

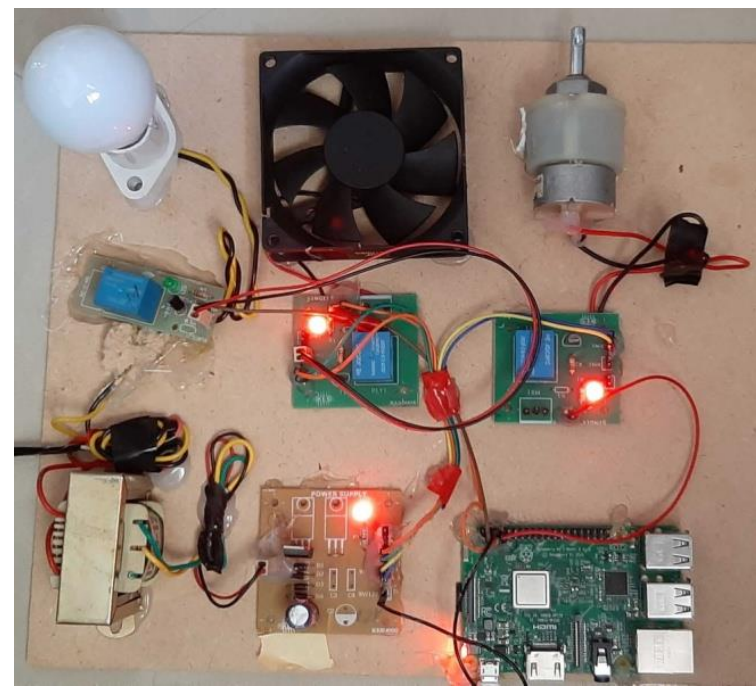

Fig. 11: Google voice assistance for light off

\section{CONCLUSION}

In this paper we developed home appliances (fan, electric tubes, refrigerator and washing machine) organize using Google voice assistance with assist of raspberry $\mathrm{Pi}$. Development of such Smart Home achieve by using Internet of Things technologies. This system is human friendly and more secure.

\section{REFERENCES}

1. Home Automation Using ATmega328 Microcontroller and Android Application, S.Anusha1, M.Madhavi2, R.Hemalatha3. International Research Journal of Engineering and Technology (IRJET), Volume: 02 Issue: 06 | Sep-2015.

2. Internet of Things: Ubiquitous Home Control and Monitoring System using Android based Smart Phone, Rajeev Piyare. International Journal of Internet of Things 2013, 2(1): 5-11.

3. Design and Implementation of a WiFi Based Home Automation System, Ahmed ElShafee, Karim AlaaHamed. World Academy of Science, Engineering and Technology International Journal of Computer, Electrical, Automation, Control and Information Engineering Vol. 6, No. 8, 2012.

4. Y.C. You, Cloud-based smart home automation, Thesis, Southern Taiwan University of Science and Technology, Communication Engineering Research Institute, 2013.

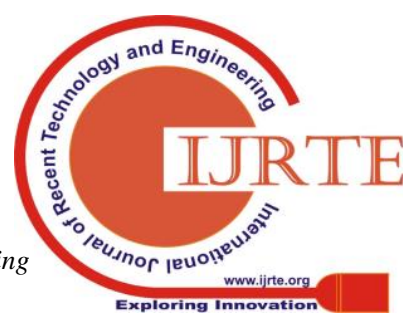

